\title{
Laser power and Scanning Speed Influence on the Mechanical Property of Laser Metal Deposited Titanium-Alloy
}

\author{
Rasheedat M. Mahamood • Esther T. Akinlabi • \\ Stephen Akinlabi
}

Accepted: 25 November 2014 / Published online: 4 December 2014

C) Springer New York 2014

\begin{abstract}
The influence of the laser power and the scanning speed on the microhardness of the Laser Metal Deposited Ti6A14V, an aerospace Titanium-alloy, was studied. Ti6Al4V powder was deposited on the Ti6Al4V substrate using the Laser Metal Deposition (LMD) process, an Additive Manufacturing (AM) manufacturing technology. The laser power was varied between $1.8 \mathrm{~kW} 3 \mathrm{~kW}$ and the scanning speed was varied between $0.05 \mathrm{~m} / \mathrm{s}$ and $0.1 \mathrm{~m} / \mathrm{s}$. The powder flow rate and the gas flow rate were kept at constant values of $2 \mathrm{~g} / \mathrm{min}$ and $2 \mathrm{l} / \mathrm{min}$ respectively. The full factorial design of experiment was used to design the experiment and to also analyze the results in the Design Expert 9 software environment. The microhardness profiling was studied using Microhardness indenter performed at a load of $500 \mathrm{~g}$ and at a dwelling time of $15 \mathrm{~s}$. The distance between indentations was maintained at a distance of $15 \mu \mathrm{m}$. The study revealed that as the laser power was increased, the microhardness was found to decrease and as the scanning speed was increased, the microhardness was found to also increase. The results are presented and fully discussed.
\end{abstract}

Keywords Laser power - Laser metal deposition (LMD) · Microhardness · Scanning Speed · Titanium alloy

R. M. Mahamood • E. T. Akinlabi

Department of Mechanical Engineering Science, University of Johannesburg, Auckland Park Campus, Johannesburg 2006, South Africa

R. M. Mahamood $(\bowtie)$

Department of Mechanical Engineering, University of Ilorin, Ilorin, Nigeria e-mail: mahamoodmr2009@gmail.com

S. Akinlabi

Department of Mechanical Engineering, Faculty of Engineering and built Environment, University of the Witwatersrand, Johannesburg, South Africa 


\section{Introduction}

Ti6Al4V is an important aerospace alloy and the most commonly used and mostly produced titanium alloy [1]. This is because it possesses excellent structural and corrosion resistance properties [2]. Despite these excellent properties, Titanium and its alloys are generally classified as difficult to machine material because of its chemical properties and high interaction between the titanium and the cutting tool materials [3]. This is why an alternative manufacturing process was required.

Additive Manufacturing (AM) process is a tool-less process and hence there will be no interaction between the machine and the material being processed which provides the best alternative manufacturing technique for processing titanium and its alloys. Laser Metal Deposition (LMD) is an important Additive Manufacturing process that is capable of fabricating parts directly from the Computer Aided Design (CAD) model of the part by adding materials layer by layer $[4,5]$. Complex shaped parts can be manufactured with LMD at a significantly lower cost as compared to the traditional manufacturing methods like turning and forming [6] that shaped parts through material removal. The laser metal deposition process is achieved by feeding powdered material or materials into the melt-pool that has been created by the laser beam on the substrate, and upon solidification, it forms a series of contours defined by the CAD data information of the component. The LMD process can also be used to repair worn out components which were prohibitive to repair in the past $[7,8]$. The LMD has the capability to handle more than one material simultaneously, and then it can be used to produce parts with functionally graded material [9]. Also because LMD produces part by adding material as against material removal in the traditional manufacturing process, then it is capable of reducing the buy-to-fly ratio for the aerospace parts [10].

The processing parameters in the LMD process has great influence on the properties of laser metal deposited parts as it has been registered in the literature [2, 11-13]. The effect of the laser power and the scanning speed on the microhardness property is scarce in the literature. In this study, the effect of laser power and the scanning speed on the microhardness properties of Ti6Al4V produced by using the laser metal deposition process was studied using the full factorial design of experiment (DOE) in order to be able to draw a statistical inference on the results obtained. The DOE is a statistical technique that allows the run of a minimum number of experiments to optimize a product or process. It involves determining the best experiments to be run in order to fit a particular mathematical model. The experiment was designed using the Design Expert 9 software, which is a type of statistical software, and the results obtained are also analyzed with this software. The results are presented and discussed in detail.

\section{Experimental Procedure}

The Ti6Al4V substrate used in this study is a $99.6 \%$ pure $72 \times 72 \times 5 \mathrm{~mm}$ sheet and the Ti6Al4V powder used is also $99.6 \%$ pure with the particle size ranging between 150 and $200 \mu \mathrm{m}$ that was supplied by VSMPO-AVISMA Corporation, Russia. The 
substrate was sandblasted and washed with acetone to roughen the surface and to improve the laser energy absorption rate. The LMD process was achieved by a Kuka robot that was carrying in its end effector an Nd-YAG laser head (by Rofin). The experimental set-up is available at the CSIR, National Laser Center Pretoria, South Africa. The Kuka robot also carries on its end effector co-axial nozzles for powder delivery into the melt-pool. A glove box was improvised to prevent contamination of the deposited part by the atmospheric oxygen and nitrogen. The laser beam was used to create a melt pool on the surface of the substrate and the Ti6Al4V powder was then delivered into the melt-pool through the powder delivery nozzles attached to the end-effector. A solid track of metal on the laser path was created upon solidification. The laser power used was set between 1.8 and $3 \mathrm{~kW}$ and the scanning speed was set between 0.05 and $0.1 \mathrm{~m} / \mathrm{s}$. The Ti6Al4V powder flow rate and the argon gas (shielding gas and carrier gas) flow rate are fixed at $2 \mathrm{~g} / \mathrm{min}$ and $2 \mathrm{l} / \mathrm{min}$ respectively. The laser beam was maintained at a focal distance of $195 \mathrm{~mm}$ above the substrate to keep the laser beam at a constant diameter of $2 \mathrm{~mm}$. The schematic of the LMD process is shown in Fig. 1.

The experiment was designed using two-level full factorial design of experiment with two replicates in the Design Expert 9 software environment. The low setting was coded as -1 and the high setting was coded as +1 and it is presented in Table 1 and the full factorial design of the two replicates is presented in Table 2

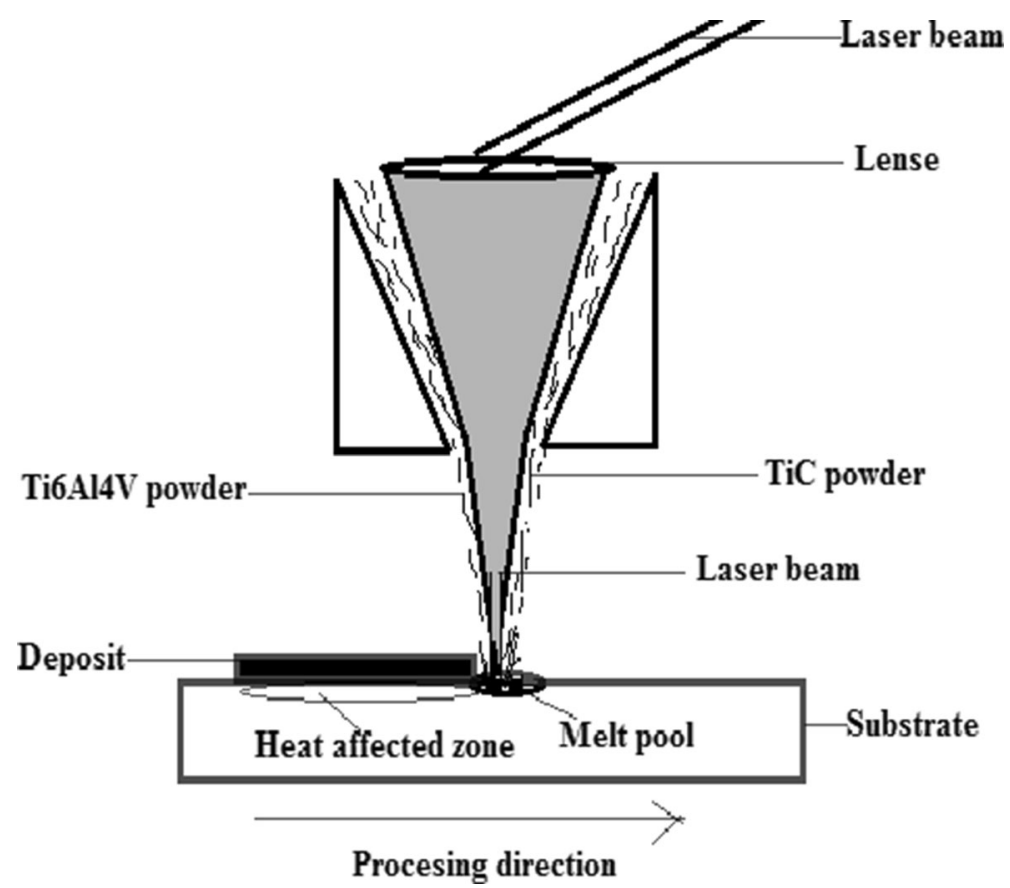

Fig. 1 Schematic of the Laser Material Deposition [16] 
Table 1 Processing parameters and code setting

\begin{tabular}{llr}
\hline Laser Power $(\mathrm{kW})$ & Scanning Speed $(\mathrm{m} / \mathrm{Sec})$ & Code \\
\hline 1.8 & 0.05 & $-1,-1$ \\
3.0 & 0.1 & $+1,+1$ \\
1.8 & 0.1 & $-1,+1$ \\
3.0 & 0.05 & $+1,-1$ \\
\hline
\end{tabular}

After the deposition process, the samples were laterally sectioned, ground and polished according to the standard metallographic preparation of Titanium and its alloys. The Microhardness profiling was carried out using the MH-3 Vickers hardness indenter by Metkon with a load of $500 \mathrm{~g}$, and a dwell time of $15 \mathrm{~s}$. The space in between indentations was kept at $15 \mu \mathrm{m}$ which is more than twice the indentation diameter according to the standard. The microhardness was taken across the deposition direction, that is, perpendicular to the deposited direction on the cross section of the sample. The samples for microstructural examination were etched with Kroll reagent after being polished. The etched samples were studied under Olympus Optical Microscope equipped with the stream software.

\section{Results and Discussion}

The microstructure of the substrate used in this study as observed under the optical microscope is shown in Fig. 2a and the macrograph of the Ti6Al4V powder is shown in Fig. 2b. The microstructure of the Ti6Al4V is characterized by alpha and beta grain structure which is typical of Ti6Al4V. The lighter parts of the microstructure are the alpha grains and the darker parts are the beta grains. The morphology of the Ti6Al4V powder is spherically shaped gas

Table 2 Processing parameters generated by the DOE

\begin{tabular}{lllll}
\hline $\begin{array}{l}\text { Std. } \\
\text { order }\end{array}$ & $\begin{array}{l}\text { Run } \\
\text { order }\end{array}$ & $\begin{array}{l}\text { Factor 1 } \\
\text { A:Laser Power }\end{array}$ & Factor 2 B:Scanning Speed & Response 1 Microhardness HV \\
\hline 2 & 1 & -1 & -1 & \\
1 & 2 & -1 & -1 & \\
4 & 3 & 1 & -1 & \\
3 & 4 & 1 & -1 & \\
5 & 5 & -1 & 1 & \\
7 & 6 & 1 & 1 & \\
6 & 7 & -1 & 1 & \\
8 & 8 & 1 & 1 & \\
\hline
\end{tabular}




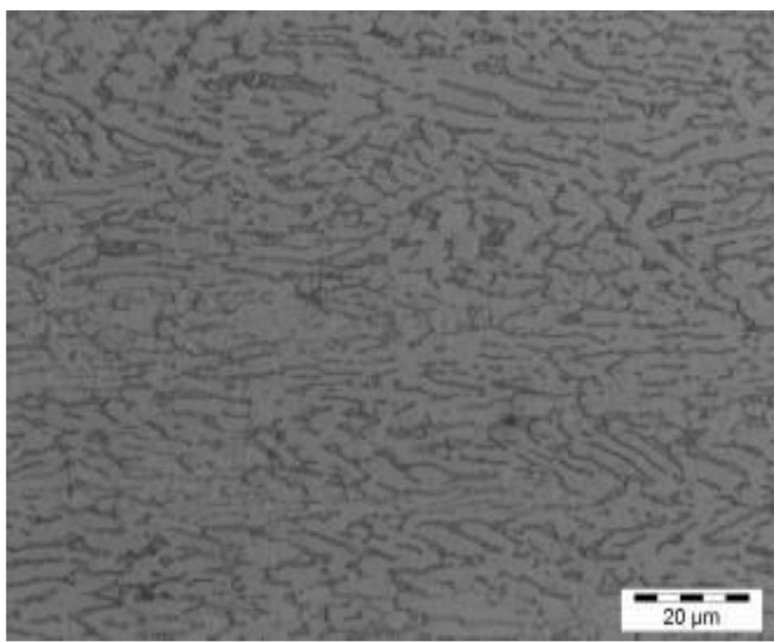

(a)

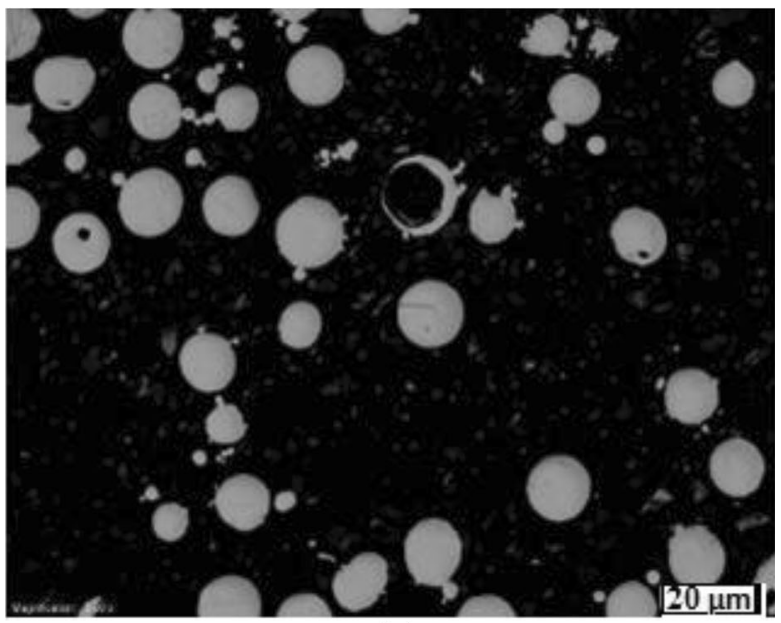

(b)

Fig. 2 (a) Microstructure of the Ti6Al4V substrate (b) Morphology of the Ti6Al4V powder

Table 3 Processing parameters

Std. order Run order Factor 1 A:Laser Power Factor 2 B:Scanning Speed Response 1 Microhardness HV

\begin{tabular}{lrrrl}
\hline 2 & 1 & -1 & -1 & 399 \\
1 & 2 & -1 & -1 & 401 \\
4 & 3 & 1 & -1 & 333 \\
3 & 4 & 1 & -1 & 337 \\
5 & 5 & -1 & 1 & 422 \\
7 & 6 & 1 & 1 & 398 \\
6 & 7 & -1 & 1 & 418 \\
8 & 8 & 1 & 1 & 396 \\
\hline
\end{tabular}


Table 4 Analysis of variance table (ANOVA)

\begin{tabular}{lccccc}
\hline Source & Sum of Squares & df & Mean Square & F Value & $p$-value Prob $>$ F \\
\hline Model & 8116.00 & 3 & 2705.33 & 541.07 & $<0.0001$ significant \\
A-Laser Power & 3872.00 & 1 & 3872.00 & 774.40 & $<0.0001$ \\
B-Scanning Speed & 3362.00 & 1 & 3362.00 & 672.40 & $<0.0001$ \\
$A B$ & 882.00 & 1 & 882.00 & 176.40 & 0.0002 \\
Pure Error & 20.00 & 4 & 5.00 & & \\
Cor Total & 8136.00 & 7 & & & \\
\hline
\end{tabular}

atomized powder. Spherical shaped powder is more preferred in the LMD process because it absorbed the laser beam better [14, 15].

The results of the microhardness are presented in Table 3. The results were analyzed in the Design Expert 9 software environment.

The Analysis of Variance (ANOVA) for the selected model is presented in Table 4. The Model's F-value of 541.07 implies that the model is significant. There is only a $0.01 \%$ chance that an F-value this large could occur due to noise. The values of "Prob $>$ F" less than 0.0500 indicates that the model terms are significant. For this model, the factors A, B and AB are significant model terms.

The coefficient of determinants 'R-Squared' values are presented in Table 5. Rsquared is the coefficient of determination and it can range between 0 and 1; it represents the percentage of the variation observed that can be explained by the correlation.

The "Predicted R-Squared" of 0.9902 is in a reasonable agreement with the "Adjusted R-Squared" of 0.9957 because; the difference between them is less than 0.2 . Also the "Adequate Precision" measures the signal to noise ratio. A ratio greater than 4 is desirable. In this model the ratio of 53.759 indicates an adequate signal. Therefore this model can be used to navigate the design space. The estimates of coefficient at $95 \%$ confidence level are presented in Table 6 . The final equation is presented in Eq. 1.

$$
\text { Microhardness }=+388.00-22.00 * \mathrm{~A}+20.50 * \mathrm{~B}+10.50 * \mathrm{AB}
$$

Where $\mathrm{A}$ is the laser power and $\mathrm{B}$ is the scanning speed.

The graphical analysis of the residual is shown in Fig. 3. The residuals are seen to be randomly distributed, which is desirable. The graph of predicted microhardness versus the actual experimental microhardness data is shown in Fig. 4. From Fig. 4, the model is shown to be in good agreement with the actual experimental data.

Table 5 Coefficient of Determinant

\begin{tabular}{lrlr}
\hline Std. Dev. & \multicolumn{1}{c}{2.24} & R-Squared & 0.9975 \\
\hline Mean & 388.00 & Adj R-Squared & 0.9957 \\
C.V. \% & 0.58 & Pred R-Squared & 0.9902 \\
PRESS & 80.00 & Adeq Precision & 53.759 \\
\hline
\end{tabular}


Table 6 Estimates of coefficients

\begin{tabular}{lllllll}
\hline Factor & $\begin{array}{l}\text { Coefficient } \\
\text { Estimate }\end{array}$ & df & $\begin{array}{l}\text { Standard } \\
\text { Error }\end{array}$ & $\begin{array}{l}\text { 95\% CI } \\
\text { Low }\end{array}$ & $\begin{array}{l}\text { 95\% CI } \\
\text { High }\end{array}$ & VIF \\
\hline Intercept & 388.00 & 1 & 0.79 & 385.81 & 390.19 & 1.00 \\
A-Laser Power & -22.00 & 1 & 0.79 & -24.19 & -19.81 & 1.00 \\
B-Scanning Speed & 20.50 & 1 & 0.79 & 18.31 & 22.69 & 1.00 \\
AB & 10.50 & 1 & 0.79 & 8.31 & 12.69 & \\
\hline
\end{tabular}

The micrograph of the sample at the laser power of $3.0 \mathrm{~kW}$ and the scanning speed of $0.05 \mathrm{~m} / \mathrm{s}$ showing the indentations that was taken perpendicular to the deposition direction is shown in Fig. 5. The main effect plot of the microhardness against the laser power is shown in Fig. 6. The microhardness was found to decrease as the laser power was increased. This was because, as the laser power was increased, the melt pool created on the surface of the substrate becomes bigger and the bigger the melt pool, the longer it takes for the melt pool to cool down. This results in the formation of Widmastätten alpha microstructure.

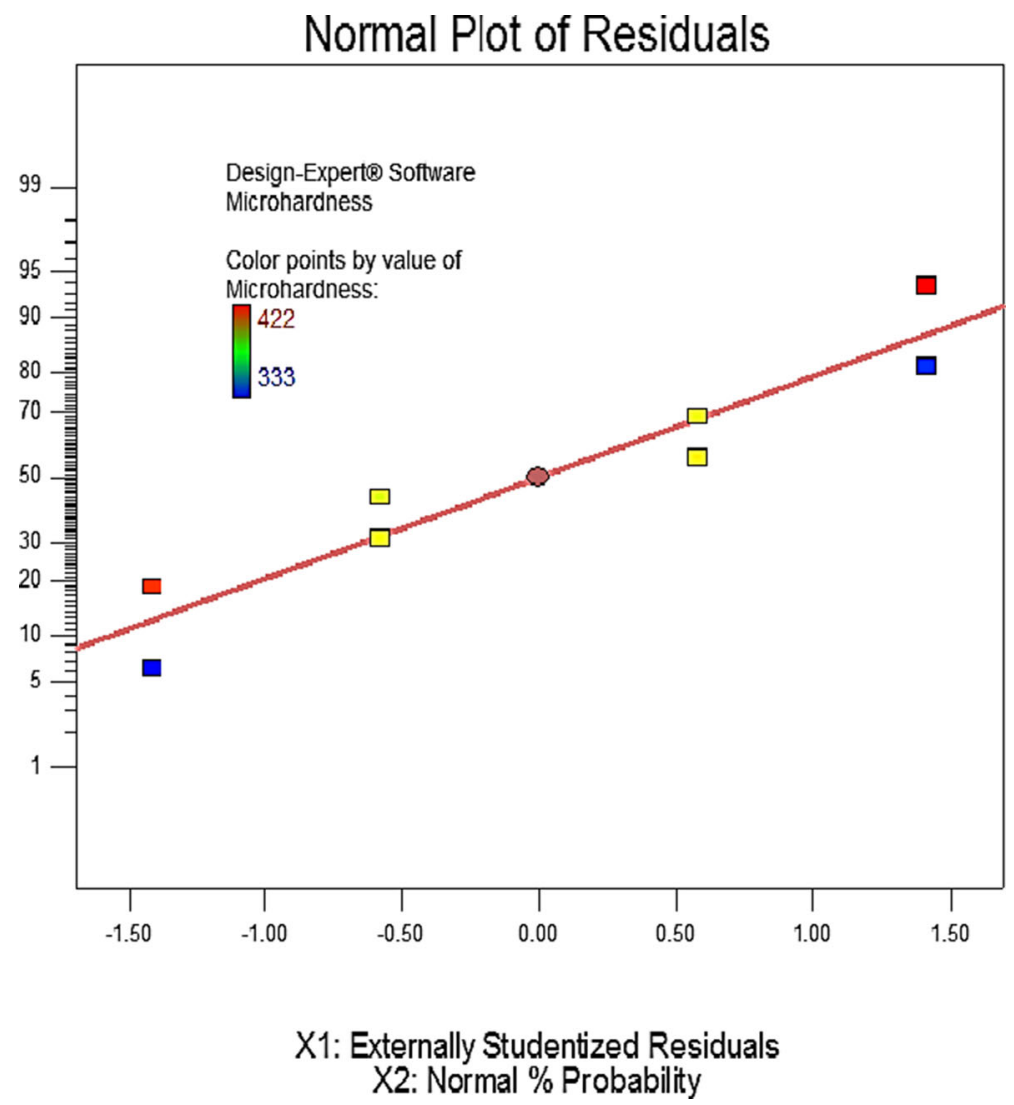

Fig. 3 Normal plot of the residuals 


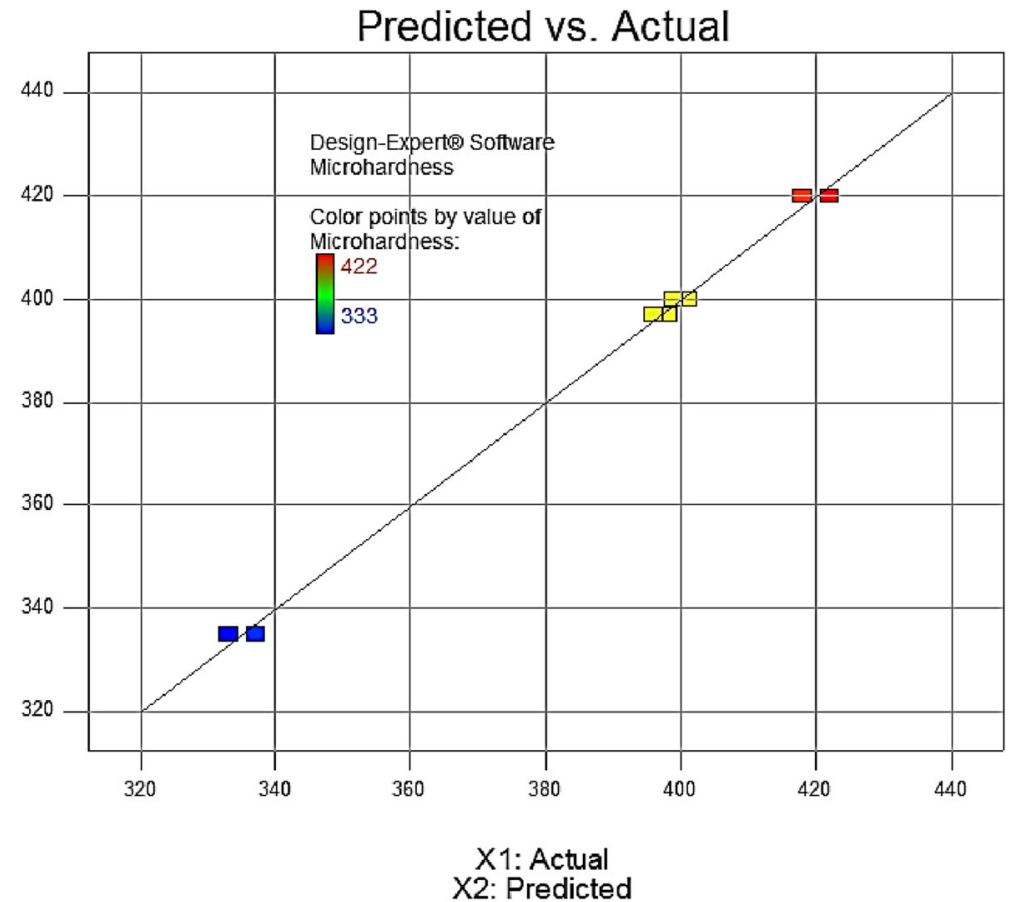

Fig. 4 Graph of Predicted against the actual experimental data

At low laser power the melt pool created on the substrate by the laser beam is smaller than the melt pool created at higher laser power and it cools down rapidly resulting in the formation of martensite in the microstructure as shown in Fig. 7a. The martensitic alpha microstructure is very hard and is responsible for the higher microhardness observed at low laser power. The slow cooling at higher laser power resulted in the Widmastätten or basket woven microstructure as shown in Fig. 7b. The

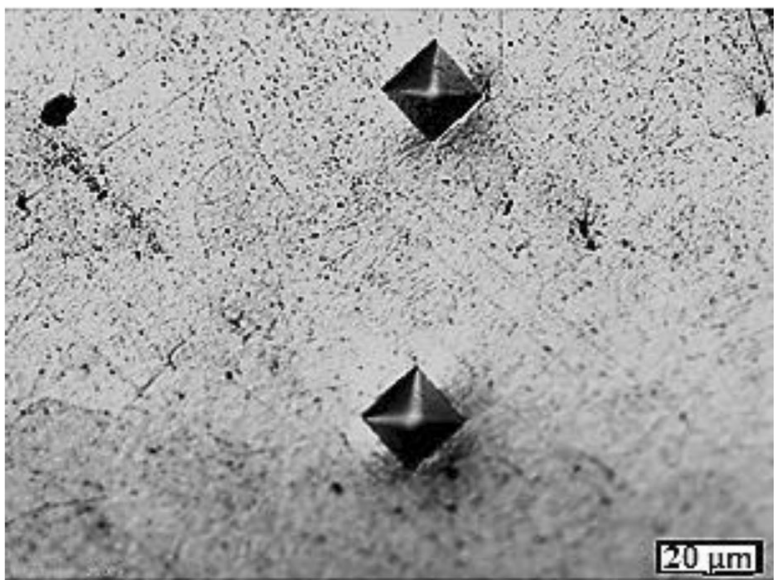

Fig. 5 Micrograph of sample at laser power of $3.0 \mathrm{~kW}$ and scanning speed of $0.05 \mathrm{~m} / \mathrm{s}$ showing the indentation 


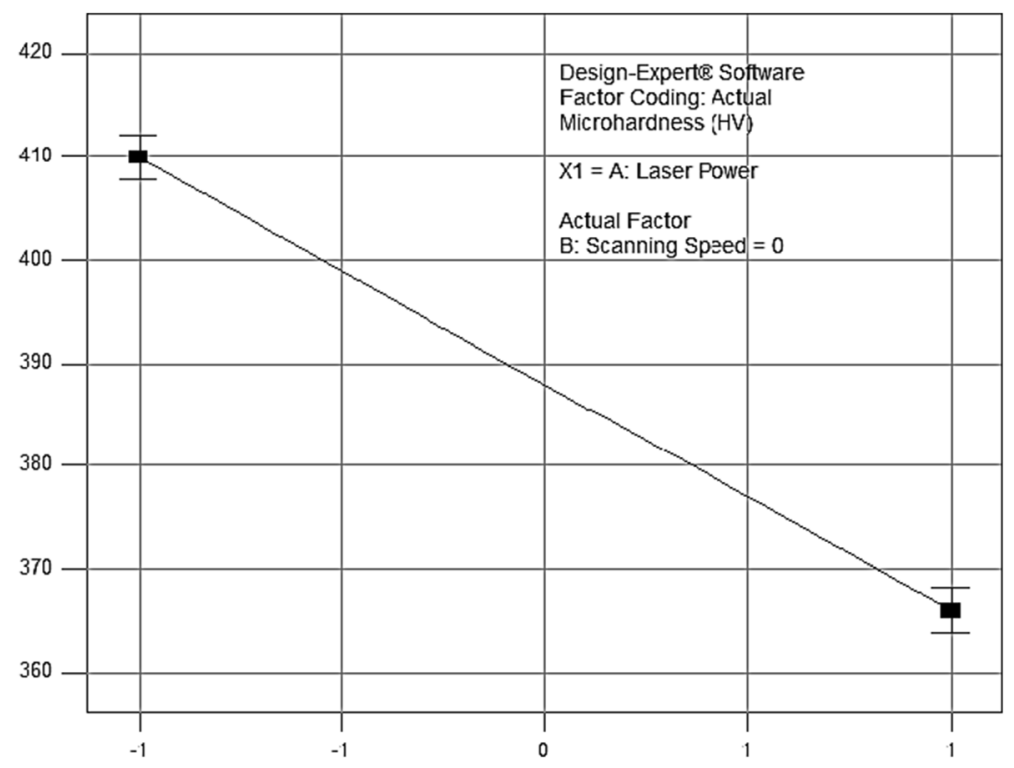

X1: A: Laser Power

Y: Microhardness (HV)

Fig. 6 The main effect plot of microhardness against laser power

Widmastätten alpha is soft and it is responsible for the lower microhardness value at higher laser power.

The maineffect plot of the microhardness against the scanning speed is shown in Fig. 8. The microhardness is found to increase as the scanning speed was increased. The reason for this behaviour is that, at low scanning speed, the laser material interaction time is high and the effect is similar to what happens at high laser power that resulted in larger melt pool and hence low microhardness values. Larger melt pool takes longer time to cool down resultin in the formation of Widmastätten alpha microstructure. The Widmastätten alpha microstructure is responsible for the low in the microhardness because it is soft.

At higher scanning speed, the laser material interaction time is low and the melt pool created by the laser beam is smaller than the melt pool created at lower scanning speed. This resulted in rapid solidification and cooling which is similar to what happened at low laser power and it is responsible for the higher microhardness value at higher laser power.

The interaction between the laser power and the scanning speed is shown in Fig. 9 and the surface plot of the microhardness against the laser power and the scanning speed is shown in Fig. 10. Strong interaction is found to exist between the laser power and the scanning speed. The microhardnes was found to be higher at low laser power and higher scanning speed than at higher laser power and lower scanning speed. This is a strong interaction. The reason for the lower microhardness can be attributed to the fact that the metal becomes softer at higher laser power and higher scanning speed. This is because, the melt pool created at higher laser power is larger and it takes longer to solidifies and cool down thereby resulting in the formation of more Widmastätten alpha microstructure. At lower laser power and higher scanning speed, the solidifaction rate 


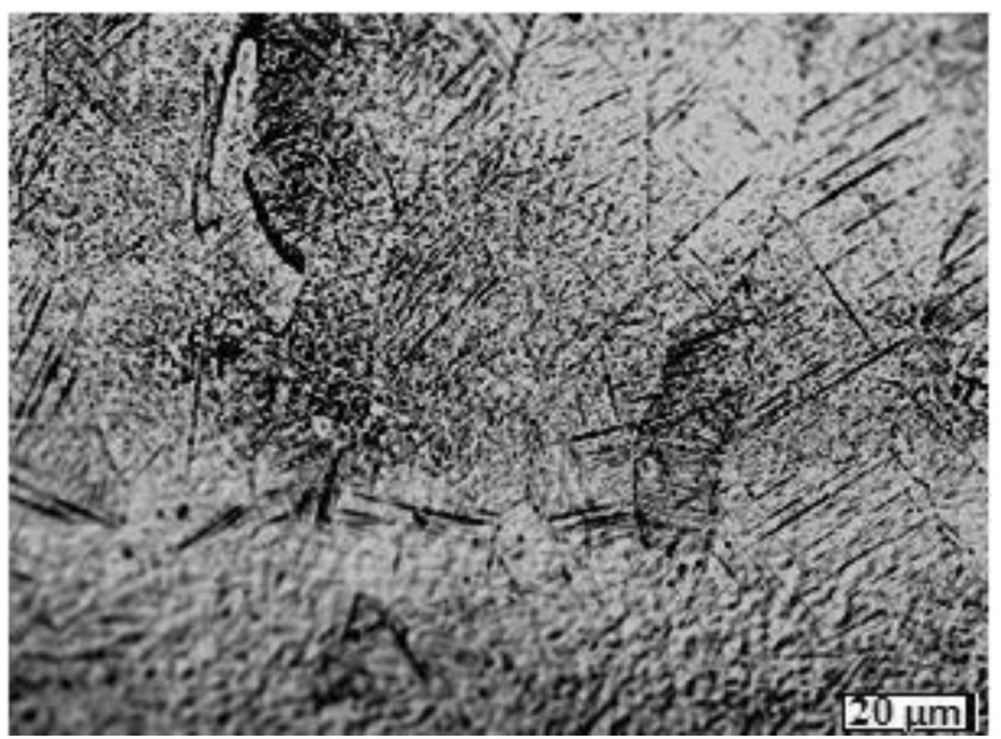

(a)

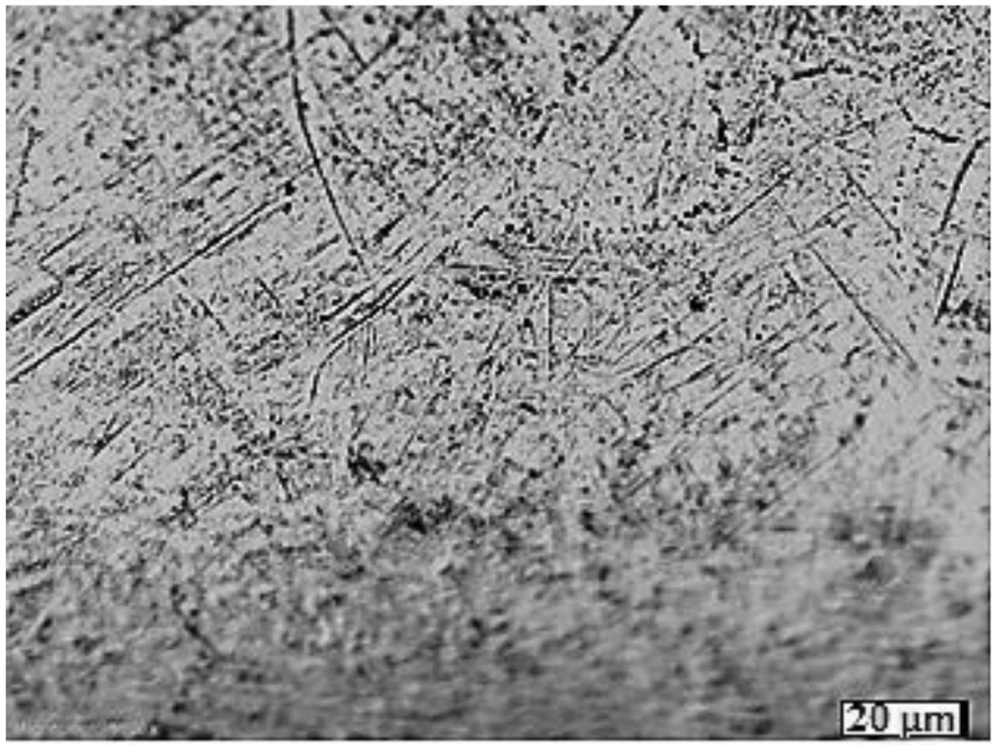

(b)

Fig. 7 The micrograph of sample at (a) laser power of $1.8 \mathrm{~kW}$ and scanning speed of $0.05 \mathrm{~m} / \mathrm{s}$ (sample A) and (b) laser power of $3.0 \mathrm{~kW}$ and scanning speed of $0.05 \mathrm{~m} / \mathrm{s}$ (sample D)

was very high as a result of the smaller melt pool created by the laser beam which resulted in higher microhardness. On the other hand, at higher laser power and lower scanning speed, the laser material interaction time is longer thereby creating a larger meltpool that takes more time to solidify and resulted in formation of mostly Widmastätten alpha microstructure which causes the low microhardness value. 


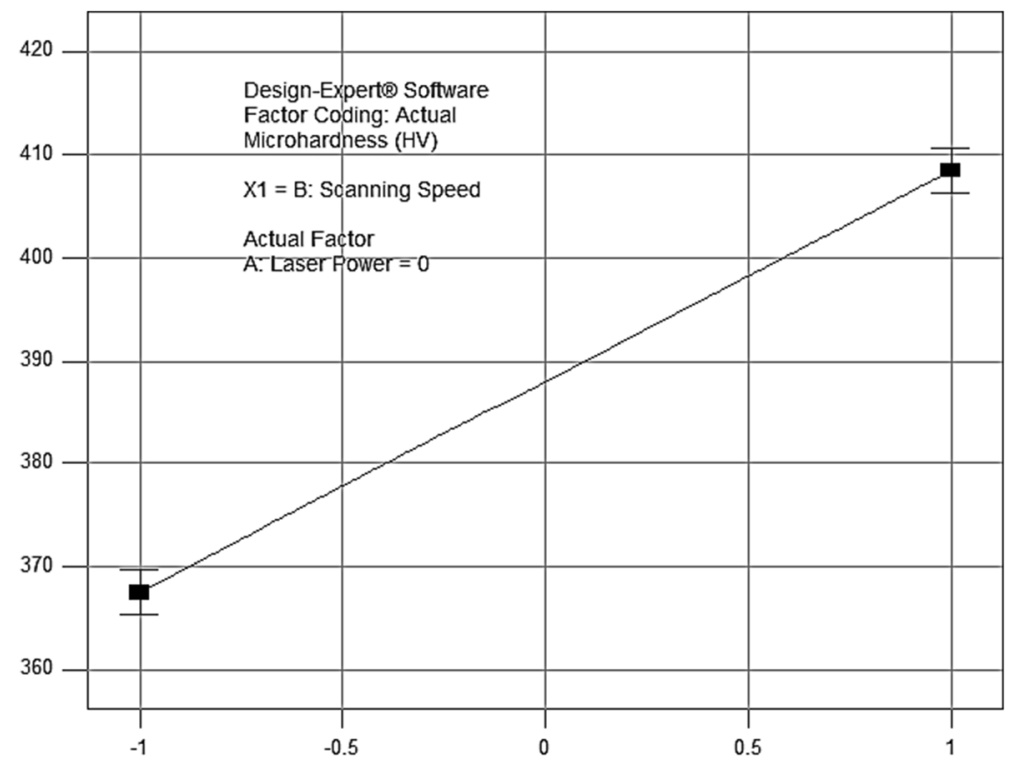

X1: B: Scanning Speed

Y: Microhardness (HV)

Fig. 8 The main effect plot of microhardness against scanning speed

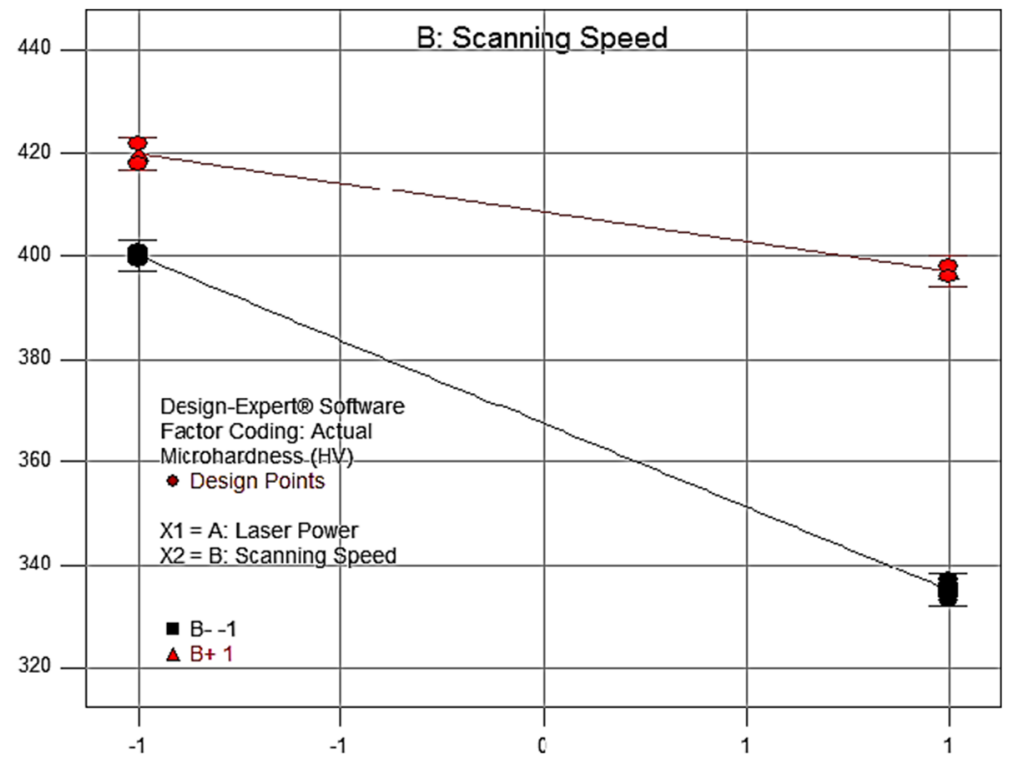

X1: A: Laser Power

Y: Microhardness (HV)

Fig. 9 Interaction plot of the microhardness against laser power scanning speed 


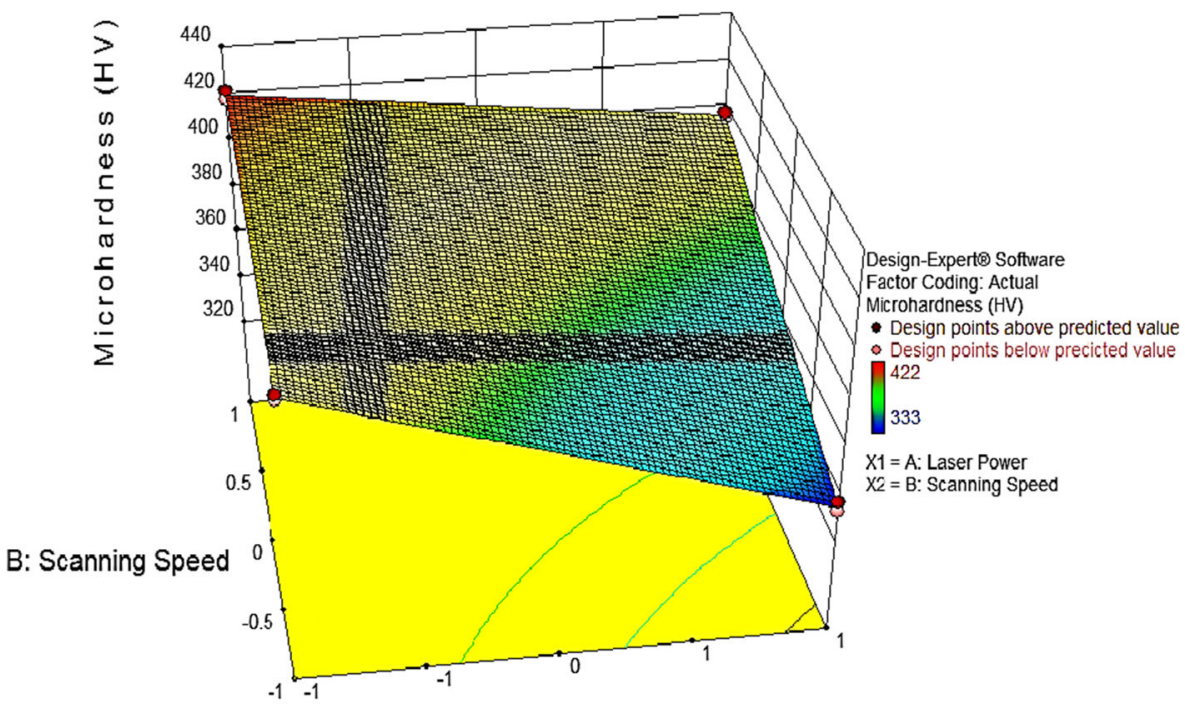

A: Laser Power

Fig. 10 The surface plot of the microhardness against the laser power and the scanning speed

\section{Conclussion}

The effect of the laser power and the scanning speed on the microhardness has been studied. Ti6Al4V powder was deposited on the Ti6Al4V substrate using the LMD process. The laser power was varied between 1.8 and $3.0 \mathrm{~kW}$ and the scanning speed was varied between 0.05 and $0.1 \mathrm{~m} / \mathrm{s}$. The gas flow rate and the powder flow rate were kept constant at values of $2 \mathrm{l} / \mathrm{min}$ and $2 \mathrm{~g} / \mathrm{min}$ respectively. The experiment was designed and analyzed using the Design Expert 9 software. The study revealed that as the laser power was increased, the microhardness was found to decrease, but as the scanning speed was increased the microhardness was found to increase. A very strong interaction was observed between the laser power and the scanning speed. The microhardness was found to be higher at lower laser power and higher scanning speed than when compared to the microhardness observed at higher laser power and lower scanning speed. This study shows that there is need for the right combination of the processing parameters in order to achieve the required microhardness value and that the LMD process can be used to produce part with an improved microhardness value when the right combination of processing parameters are used.

Acknowledgments This work is supported by the Rental Pool Grant of the National Laser Centre - Council of Scientific and Industrial Research (NLC-CSIR), Pretoria South Africa.

\section{References}

1. Peters, M., Kumpfert, J., Ward, C.H., Leyens, C.: Titanium alloys for aerospace applications titanium and titanium alloys. Adv. Eng. Mater. 5, 419-427 (2003) 
2. Lu, Y., Tang, H.B., Fang, Y.L., Liu, D., Wang, H.M.: Microstructure evolution of sub-critical annealed laser deposited Ti-6Al-4V alloy. Mater. Des. 37, 56-63 (2012)

3. Wang, Z.M., Ezugwu, E.O.: Titanium alloys and their machinability a review. J. Mater. Process. Technol. 68, 262-270 (1997)

4. Toyserkani, E., Khajepour, A.: A mechatronics approach to laser powder deposition process". Mechatronics 16(10), 631-641 (2006)

5. Scott J., Gupta N., Wember C., Newsom S., Wohlers T., and Caffrey T. "Additive manufacturing: status and opportunities", Science and Technology Policy Institute, Retrieved 11th March 2013, from (2012) https://www.ida.org/stpi/occasionalpapers/papers/AM3D 33012 Final.pdf

6. Mahamood M.R., Akinlabi E. T., Shukla M., and Pityana S., "Effect of Laser Power on Material Efficiency, Layer Height and Width of Laser Metal Deposited Ti6Al4V", Proceedings of the World Congress on Engineering and Computer Science 2012 Vol II WCECS 2012, October 24-26, 2012, San Francisco, USA, pp. 1433-1438 (2012)

7. Pinkerton, A.J., Wang, W., Li, L.: Component repair using laser direct metal deposition. Proc. IMechE Part B: J Eng. Manuf. 222, 827-836 (2008)

8. Cottam, R., Brandt, M.: Laser cladding of ti-6al-4v powder on ti-6al-4v substrate: effect of laser cladding parameters on microstructure. Phys. Procedia 12, 323-329 (2011)

9. R. M. Mahamood, E. T. Akinlabi, M. Shukla and S. Pityana, Functionally Graded Material: An overview, Lecture Note in Engineering, WCE 2012, July 4-6,2012, 3, 1593-1597 London, United Kingdom, (2012)

10. Brandl, E., Michailov, V., Viehweger, B., Leyens, C.: Deposition of Ti-6Al-4 V using laser and wire, part I: Microstructural properties of single beads. Surface \& Coat. Technol. 206, 1120-1129 (2011)

11. R. M. Mahamood, E. T. Akinlabi, M. S. and Sisa Pityana, Effect of Laser Power on Material Efficiency, Layer Height and Width of Laser Metal Deposited Ti6A14V, World Congress of Engineering and Computer Science (WCECS), San Francisco 2012, 24-26 October 2012, vol. 2, pp. 1433-1435 (2012)

12. Esther T. Akinlabi, Rasheedat M. Mahamood, Mukul Shukla and Sisa Pityana, Effect of Scanning Speed on Material Efficiency of Laser Metal Deposited Ti6Al4V, Accepted for oral presentation at the World Academy of Science, Engineering and Technology (WASET 2012), 28-28 November 2012 (2012)

13. R. M. Mahamood, E. T. Akinlabi, M. Shukla and S. Pityana, Laser Metal Deposition of Ti6Al4V: A Study on the Effect of Laser Power on Microstructure and Microhardness, Accepted for oral presentation at the 2013 International Multiconference of Engineering and Computer Science (IMECS 2013), March 2013 (2012)

14. Dalgarno, K.W., Wright, C.S.: Approaches to processing metals and ceramics through laser scanning of powder beds - a review. Powder. Met. Prog. 1(1), 70-79 (2001)

15. C. T. Schade, T. F. Murphy and Chris Walton Development Of Atomized Powders for Additive Manufacturing, Powder Metallurgy Word Congress, Accessed on 2nd July 2014 available at (2014) http://www.gkn.com/hoeganaes/media/Tech\%20Library/Schade-Atomized $\% 20$ Powders $\% 20$ for $\%$ 20Additive $\% 20$ Manufacturing $\% 20 \% 281 \% 29$.pdf

16. Mahamood, R.M., Akinlabi, E.T., Shukla, M., Pityana, S.: Characterization of laser deposited Ti6A4V/ TiC composite. Lasers in Engineering. 29(3-4), 197-213 (2014) 